\title{
Effects of 14 weeks of progressive endurance training on energy expenditure in elderly people
}

\author{
Béatrice Morio ${ }^{1}$, Christophe Montaurier ${ }^{1}$, Gisèle Pickering ${ }^{2}$, Patrick Ritz ${ }^{1}$, Nicole Fellmann ${ }^{2}$, \\ Jean Coudert ${ }^{2}$, Bernard Beaufrère ${ }^{1}$ and Michel Vermorel $^{3 *}$ \\ ${ }^{1}$ Centre de Recherche en Nutrition Humaine, LNH, BP 321-58 rue Montalembert, 63009 Clermont-Ferrand cédex 1, France, \\ ${ }^{2}$ Laboratoire de Physiologie-Biologie du Sport, Faculté de Médecine, 28 Place H. Dunant 63001 Clermont-Ferrand, France, \\ ${ }^{3}$ INRA, U. Métabolismes Energétique et Lipidique, 63122 Saint-Genes-Champanelle, France
}

(Received 17 March 1998 - Revised 11 June 1998 - Accepted 6 July 1998)

\begin{abstract}
Effects of progressive endurance training on energy expenditure (EE) were studied in thirteen elderly sedentary subjects (62.8 (SD 2.3) years) after 7 and 14 weeks of training. Daily EE (DEE) and energy cost of the various usual activities were measured over $48 \mathrm{~h}$ by whole-body indirect calorimetry. Free-living DEE $\left(\mathrm{DEE}_{\mathrm{FLC}}\right)$ was calculated from $7 \mathrm{~d}$ activity recordings and the energy costs of activities were measured in the calorimeters using the factorial method. $\mathrm{DEE}_{\mathrm{FLC}}$ did not vary significantly throughout the training period despite the additional energy cost of training sessions $(0.60(\mathrm{SD} 0.15) \mathrm{MJ} / \mathrm{d})$, because energy expended during free-living activities $\left(\mathrm{EE}_{\mathrm{ACT}}\right)$ decreased by $4.8(\mathrm{SD} 7.1) \%(P<0.05)$ and $7.7(\mathrm{SD} 8.6) \%(P<0.01)$ after 7 and 14 weeks of training respectively. Measurements in the calorimeters showed that sleeping metabolic rate transiently increased by 4.6 (SD 3.2) \% after 7 weeks of training $(P<0.001)$ and returned to its initial level after 14 weeks of training. BMR was 7.6 (SD 7.0) \% $(P<0.01)$ and 4.1 (SD 6.1) \% $(P=\mathrm{NS})$ higher after 7 and 14 weeks of training respectively, than before training. Likewise, diet-induced thermogenesis increased from 3.7 (SD 2.5) to 7.2 (SD 2.8) \% energy intake after 7 weeks of training $(P<0.05)$, and returned to its initial level after 14 weeks of training (4.2 (SD 2.6) \% energy intake). Despite these changes, energy expended during activities and the corresponding DEE did not vary throughout the training period. It was concluded that: (1) $\mathrm{DEE}_{\mathrm{FLC}}$ remained constant throughout the training period due to a compensatory decrease in free-living $\mathrm{EE}_{\mathrm{ACT}}$; (2) progressive endurance training induced a transient increase in sleeping metabolic rate, BMR and diet-induced thermogenesis after 7 weeks which was not reflected in the energy expended during activities and DEE.
\end{abstract}

Energy expenditure: Endurance training: Elderly people

Intensity and duration of spontaneous physical activities decrease progressively during ageing (Prentice, 1992) in association with muscle mass loss (Flynn et al. 1989) and a decline in functional capacities (Chatard \& Denis, 1994; Evans, 1996). Endurance training could slow down this process even in elderly subjects, in whom it has been shown to improve maximal aerobic uptake $\left(\mathrm{VO}_{2 \max }\right)$ (Tzankoff et al. 1972; Meredith et al. 1989) and body composition. This type of training has been shown to induce loss of fat mass in the short term (Hersey et al. 1994) and to promote preservation of fat-free mass (FFM) in the long term (Horber et al. 1996). These training-related changes in body composition could induce alterations in daily energy expenditure (DEE). Moreover, endurance training could be associated with alterations in one or several components of DEE such as BMR, diet-induced thermogenesis (DIT) and energy expended during activities. However, in the large number of studies dealing with the effects of physical training in elderly people, very few have investigated the adaptations of energy metabolism. In elderly subjects, only fragmented data are yet available and contradictory results are observed. A single study examined the effects of physical training on energy cost of activities and showed no significant variations in energy expended while walking at a given speed after 6 months of endurance training (Tzankoff et al. 1972). Regarding the effects of physical training on BMR, an $11 \%$ increase in BMR was observed after 8 weeks of endurance training (Goran \& Poehlman,

\footnotetext{
Abbreviations: BW, body weight; DEE, daily energy expenditure; $\mathrm{DEE}_{\mathrm{FLC}}$, free-living daily energy expenditure; DIT, diet-induced thermogenesis; $\mathrm{EE}$, energy expenditure; $\mathrm{EE}_{\mathrm{ACT}}$, energy expended during spontaneous daily activities; FFM, fat-free mass; MAP, maximal aerobic power; SMR, sleeping metabolic rate; $\mathrm{VO}_{2 \max }$, maximal aerobic uptake.

*Corresponding author: Dr Michel Vermorel, fax +33 4736246 39, email vermorel@clermont.inra.fr
} 
1992) but not after 12 or 24 weeks of endurance training (Tzankoff et al. 1972; Meredith et al. 1989). Various results have also been obtained on training-effects on DIT. A significant positive relationship was found between physical activity level and DIT in a large population of adults aged 16-65 years (Tataranni et al. 1995), but not in people aged 20-33 and 63-87 years (Visser et al. 1995). Moreover, no clear conclusions could be drawn from longitudinal studies conducted in young adults since DIT was either not significantly altered or was increased after a period of training (for a review, see Pi-Sunyer \& Segal, 1992). In the single study by Goran \& Poehlman (1992) on the effects of 8 weeks of intensive endurance training on free-living DEE, it was concluded that elderly people reduced their spontaneous activities to compensate for the increased energy expenditure of the training sessions.

The present study aimed to determine the time-course effects of endurance training on free-living DEE and on its components, in sedentary elderly subjects. Measurements were obtained for thirteen subjects before, and after 7 and 14 weeks of a progressive training programme which was adapted to their physical capacities. The effects of training on the components of DEE (sleeping metabolic rate (SMR), BMR, DIT and the energy costs of usual and standardized activities) were studied using whole-body indirect calorimetry measurements, while free-living DEE was determined from activity recordings using the factorial method (Morio et al. 1997b).

\section{Subjects and methods}

\section{Subjects}

Thirteen subjects (five men and eight women) aged 62.8 (SD 2.3) years completed the 14-week endurance training programme. All subjects were previously sedentary, i.e. they did not participate in any regular exercise programme. They were non-smokers, not suffering from any diagnosed disease and under no medication known to influence energy metabolism. All women were postmenopausal and none was receiving oestrogen replacement therapy. All subjects had taken a medical examination and had successfully performed a maximal aerobic power (MAP) test on a cycle ergometer, under cardiovascular supervision by a cardiologist. The study protocol was approved by the regional Medical School Ethical Committee.

\section{General study design}

After completion of the MAP test, volunteers recorded their daily activities (nature and duration) during $7 \mathrm{~d}$ in freeliving conditions. This allowed us to calculate free-living DEE (see later) and to establish an activity programme for the first day in the calorimeters. Thereafter, the subjects spent $18 \mathrm{~h}$ (one night and one morning) in the calorimeters to become accustomed to the equipment. At $7 \mathrm{~d}$ later, they spent $60 \mathrm{~h}$ (one adaptation night and $48 \mathrm{~h}$ ) in the calorimeters where energy expenditure (EE) and heart rate were measured continuously. During the first day in the calorimeters, subjects followed an activity programme simulating their free-living habits, whereas during the second day, they followed a standard light-intensity activity programme. Body composition measurements were performed on a separate day. The full set of measurements, with the exception of the period of adaptation to the calorimeters, was performed again after completion of 7 and 14 weeks of endurance training. As we required the subjects to maintain a stable body weight (BW), BW was monitored weekly and individual dietary advice was given when necessary.

\section{Maximal aerobic power test: guidelines for the training exercises, and energy expenditure calculations}

The MAP tests were performed on a cycle ergometer (Ergomeca, Monark, Sweden). The subjects performed several successive $2.5 \mathrm{~min}$ steps against increasing power output (by $30 \mathrm{~W}$ steps) until exhaustion. The pedalling frequency was maintained at $60 \mathrm{rev} . / \mathrm{min}$ and the heart rate was recorded continuously (Schiller AG, Cardiovit CS-6/12, Baar, Switzerland). $\mathrm{O}_{2}$ and $\mathrm{CO}_{2}$ fractions in expired air were measured continuously by open-circuit spirometry and averaged for every $30 \mathrm{~s}$ using an automated on-line system (Med Graphics CPX I D, St Paul, MN, USA). The three criteria for reaching the $\mathrm{VO}_{2 \max }$ were: a plateau in $\mathrm{O}_{2}$ consumption, an RQ higher than $1 \cdot 1$ and a maximal heart rate close to the theoretical maximal heart rate (220 - age (years)).

Blood pressure and earlobe blood samples for the measurement of lactate concentration (Analox LM5; Amalox Instruments Ltd., London, UK) were taken before and at the end of each $2.5 \mathrm{~min}$ step of the test. $\mathrm{VO}_{2 \max }$, the corresponding maximal heart rate and MAP were determined. Lactic threshold was determined from blood lactate concentration kinetics during the MAP test. The corresponding heart rate and power output were used as guidelines for subsequent individualized training.

EE was calculated from gas exchanges using Weir's (1949) equation at each step, excluding the first and last steps.

\section{Endurance training programme}

The training programme consisted of supervised cycling on a Monark cycle ergometer three times per week for 14 weeks. All training sessions began with a 10 min warm-up period and ended with a $10 \mathrm{~min}$ cooling-down period on the cycle ergometer. Regarding the training exercise, power output was adapted to achieve the target heart rate. During the first 2 weeks of training, the training exercise consisted of $20 \mathrm{~min}$ at heart rate corresponding to $50 \%$ $\mathrm{VO}_{2 \max }$. Thereafter, it consisted of interval-training episodes alternating between heart rate corresponding to $50 \% \mathrm{VO}_{2 \max }$ for $5 \mathrm{~min}$ and heart rate at lactic threshold for 3 min (Massé-Biron et al. 1993; Fig. 1). Intensity and duration of the exercise were gradually increased, therefore, the interval-training episodes alternated between heart rate at lactic threshold and heart rate above lactic threshold during the second 7-week period.

\section{Body-composition measurements}

BW was measured to the nearest $0.1 \mathrm{~kg}$ on a SECA 709 scale (SECA, Les Mureaux, France). Height was measured to the nearest $2 \mathrm{~mm}$. Total body water was estimated by 


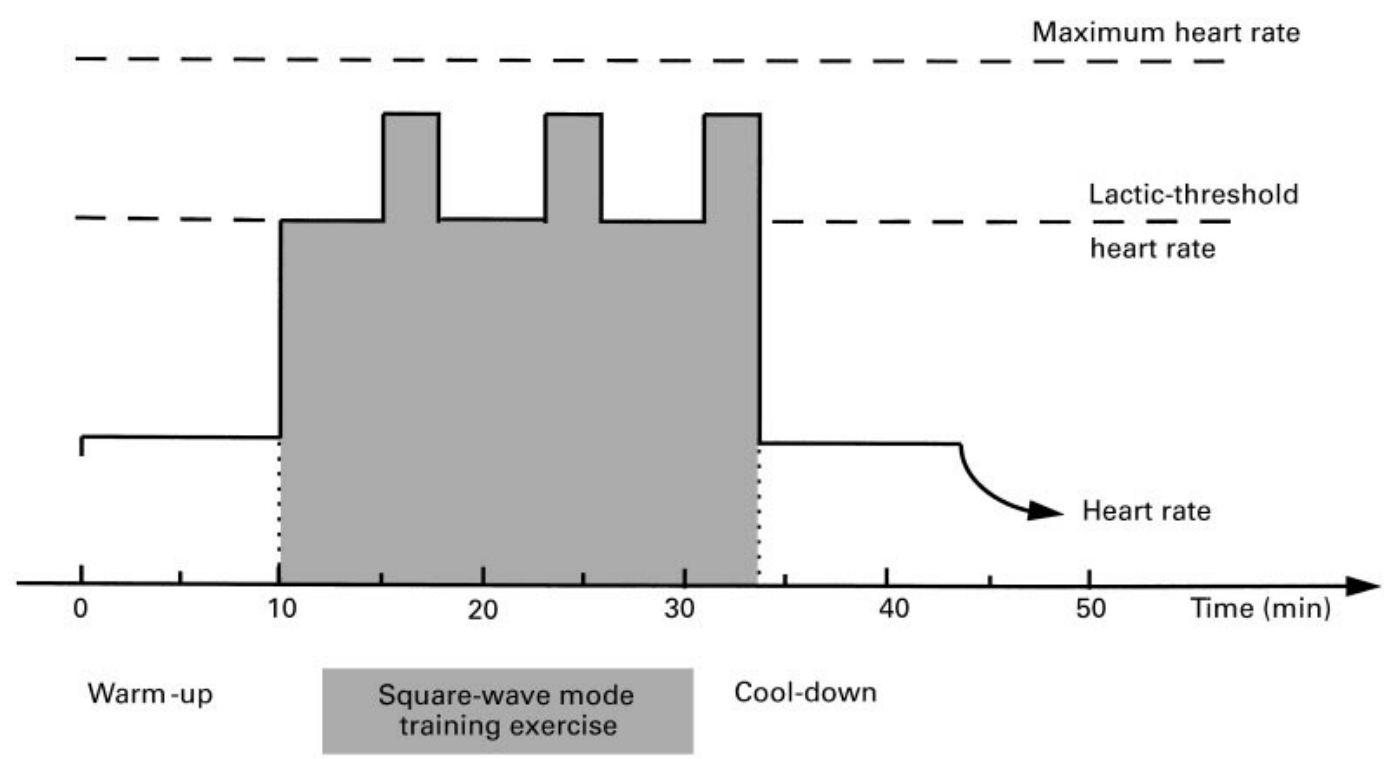

Fig. 1. Interval-training exercise on cycle ergometer: kinetics of heart rate during a training session which included a 10 min warm-up period, 25 min of interval training exercise and a $10 \mathrm{~min}$ cooling-down period. The kinetics also fit with those of power output.

isotope dilution of $\mathrm{D}_{2} \mathrm{O}$ using Coward's (1990) equation. The result was corrected for the $4 \%$ overestimation due to $\mathrm{H}$ exchanges between water and non-aqueous materials (Schoeller et al. 1980). Whole-body density was estimated from measurements of skinfold thicknesses at four sites, using the sex- and age-specific equations of Durnin \& Womersley (1974). Body fat (\%) was calculated from total body water (TBW) and whole-body density using an equation determined from water, fat and solids densities (0.9937, 0.9007 and 1.555 respectively) (Siri, 1956):

$$
\text { fat mass } \begin{aligned}
(\%)=100 \times & (2 \cdot 137 / \text { body density }-(\mathrm{TBW} / \mathrm{BW}) \\
\times & 0.774-1 \cdot 374) .
\end{aligned}
$$

FFM was calculated from BW and percentage fat mass, therefore making no assumptions about hydration of FFM.

\section{Assessment of free-living activities and daily energy expenditure}

In free-living conditions, the volunteers were asked to record their activities as accurately as possible ( $\pm 5 \mathrm{~min}$ ) for $7 \mathrm{~d}$. The various daily activities were distributed among nineteen types ranging from sleeping to cycling (Morio et al. $1997 b$ ) plus the training exercises. The corresponding freeliving DEE ( $\mathrm{DEE}_{\mathrm{FLC}}$ ) was calculated from the duration of the recorded activities and the unitary costs of the various activities (including sleep) determined for each volunteer, at each stage of the training period and during the first day in the calorimeters. Energy expended during spontaneous daily activities (free-living $\mathrm{EE}_{\mathrm{ACT}}$ ) was calculated as $\mathrm{DEE}_{\mathrm{FLC}}$ minus energy expended during sleep and during the training sessions.

\section{Activity programme during the first day in the calorimeters}

From the activities recorded during $7 \mathrm{~d}$ in free-living conditions, an appropriate activity programme was calculated for each subject to simulate mean usual physical activity. Particular attention was paid to reproduce the habitual intensity of each activity, the latter being adapted to the equipment available in the chambers as previously described (Morio et al. 1997b).

\section{Activity programmes during the second day in the calorimeters}

The activity programme during the second day in the calorimeters allowed measurement of energy expended during walking at a given speed, walking at two selfchosen speeds, light-standardized seated and standing activities, rest while watching television, sleep and basal resting conditions. The standard meal supplied at dinner provided $50 \mathrm{~kJ} / \mathrm{kg} \mathrm{BW}$ for women and $53 \mathrm{~kJ} / \mathrm{kg} \mathrm{BW}$ for men (63\% energy as carbohydrate, $25 \%$ as lipid, $12 \%$ as protein).

\section{Indirect calorimetry measurements}

$\mathrm{EE}$ and heart rate were measured continuously in two open-circuit calorimetric chambers (Morio et al. 1997a). Gas exchanges were computed from outlet air flow, differences in gas concentrations, atmospheric pressure, chamber air temperature and hygrometry. Values were corrected for the drifts and time of response of the gas analysers and the variations of the volumes of $\mathrm{CO}_{2}$ and $\mathrm{O}_{2}$ in the chambers (Vermorel et al. 1995). EE was calculated using Weir's (1949) equation from the minute-to-minute measurement of gas exchanges corrected for urinary $\mathrm{N}$ excretion.

SMR was taken as the energy expended during the last night in the calorimeters from midnight to 06.00 hours. Increases in EE above $15 \%$ associated with heart rate peaks were considered to result from waking up and were excluded from SMR. SMR was extrapolated to $8 \mathrm{~h}$. On the last morning, BMR was taken as the energy expended during 
the last $30 \mathrm{~min}$ of a $1 \mathrm{~h}$ resting period when subjects were lying in bed, awake and fasting. BMR was extrapolated to $1 \mathrm{~h}$. DIT was calculated from the difference between energy expended during $3.5 \mathrm{~h}$ after the standard meal given at dinner and during the $2 \mathrm{~h}$ resting period preceding dinner. Subjects were resting and watching television during both periods. The increase in EE was expressed in percentage units of the energy actually consumed. Energy expended during activities was determined over $30 \mathrm{~min}$ for light-intensity activities and over $15 \mathrm{~min}$ for walking.

\section{Statistical analysis}

Results are reported as means and standard deviations except for adjusted values (means with their standard errors). The unpaired Student's two-tail $t$ test was used for comparison of means between men and women. Statistical differences in body composition, functional capacities and $\mathrm{EE}$ were established during the training period using a repeated-measures ANOVA design with a confidence level of $P<0.05$. When an overall difference was found to be significant, individual stages were compared using the paired Student's two-tail $t$ test. Results were considered statistically significant at the $5 \%$ level. Significant predictors of within-subject changes in EE, except cycling EE, were determined using a step-by-step ascendant regression model. BW, FFM, fat mass and $\mathrm{VO}_{2 \max }$ were used as potential predictors. Since the power output at the different steps of the MAP test increased during the training period, variations in cycling EE were assessed on adjusted values. The latter were calculated for each subject using an analysis of covariance: power output was used as the predictor and training stage was introduced as a three-level discrete variable.

\section{Results \\ Subject characteristics}

No sex differences were found in the variations of body composition throughout the training period. On average, BW remained constant throughout the training period, although four of the thirteen subjects lost $4 \% \mathrm{BW}$. Body composition, however, changed as a result of endurance training (Table 1). Fat mass decreased by 11.9 (SD 13.6) \% (i.e. $-2.1 \mathrm{~kg})(P<0.001)$ while total body water increased by $4.0(\mathrm{SD} 6.1) \%(P=0.05)$ after 14 weeks of training. FFM did not increase significantly after 14 weeks of training $(+2.7$ (SD 4.5$) \%$, i.e. $+1.4 \mathrm{~kg}, P=0.07)$. However, it increased by $5 \%$ in the nine subjects who maintained their BW constant $(P<0.01)$, and decreased by $2 \%$ in the four subjects who lost $4 \% \mathrm{BW}$.

\section{Functional capacities}

Power output during training exercise was 1.3 (SD 0.4) MJ for men and 0.7 (SD 0.1) MJ for women at the beginning of the training period (Fig. 2). It was increased by 89 (SD 33) and 123 (SD 46) \% on average for men and women after 7 and 14 weeks of training respectively. Power output reached 2.9 (SD 1.3) MJ for men and 1.7 (SD 0.4) MJ for women after 14 weeks of training. The increment in power output resulted from a concomitant increase in intensity and duration of exercise. Because of the increase in $\mathrm{VO}_{2 \max }$, values for the mean relative intensity of training exercise were 61.1 (SD 6.4) and 63.0 (SD 6.2) \% $\mathrm{VO}_{2 \max }$ after 7 and 14 weeks of training respectively.

$\mathrm{VO}_{2 \max }$ increased by 4.8 (SD 7.9) \% ( $P=\mathrm{NS}$ ) and 13.9 (SD 7.2) \% $(P<0.001)$ after 7 and 14 weeks of training respectively. MAP increased from 116 (SD 38) to 125 (SD 39) $\mathrm{W}$ after 7 weeks of training (i.e. +8.0 (SD 7.9) \%; $P<0.001$ ) and reached 137 (SD 44) W at the end of the training period (i.e. +18.4 (SD 11.5) \%; $P<0.001)$. Maximal heart rate remained constant throughout the training period (161 (SD 11) beats/min). Heart rate at lactic threshold varied from 129 (SD 9) before training to 135 (SD 14) beats/min after 14 weeks of training $(P=N S)$. Power output at lactic threshold mainly increased during the first 7 weeks of training from 82 (SD 32) to 101 (SD 33) W (i.e. +27.2 (SD 19.4) \%; $P<0.001$ ), and reached 107 (SD 41) W after 14 weeks of training (i.e. +33.4 (SD 18.7) \%; $P<0.001$ ).

\section{Free-living daily energy expenditure}

From the activity recordings in free-living conditions, activities were distributed among six categories: sleep plus

Table 1. Characteristics of elderly subjects before training and changes in body composition and physical capacities after 7 and 14 weeks endurance training

(Mean values and standard deviations for five men and eight women)

\begin{tabular}{|c|c|c|c|c|c|c|c|}
\hline & \multicolumn{2}{|c|}{ Before } & \multicolumn{2}{|c|}{7 weeks } & \multicolumn{2}{|c|}{14 weeks } & \multirow[b]{2}{*}{ ANOVA† } \\
\hline & Mean & SD & Mean & SD & Mean & SD & \\
\hline $\begin{array}{l}\text { Age (years) } \\
\text { Height }(\mathrm{m})\end{array}$ & $\begin{array}{c}62.8 \\
1.637\end{array}$ & $\begin{array}{l}2 \cdot 3 \\
0.104\end{array}$ & & & & & \\
\hline Weight (kg) & $67 \cdot 8$ & $14 \cdot 2$ & $67 \cdot 4$ & $14 \cdot 4$ & $67 \cdot 1$ & $14 \cdot 3$ & $P=0.15$ \\
\hline Total body water $(\mathrm{kg})$ & $35 \cdot 2$ & $10 \cdot 2$ & 35.4 & $10 \cdot 1$ & $36 \cdot 7^{*}$ & 11.4 & $P=0.03$ \\
\hline Fat-free mass $(\mathrm{kg})$ & $46 \cdot 0$ & $12 \cdot 4$ & $46 \cdot 3$ & $12 \cdot 6$ & $47 \cdot 4$ & $13 \cdot 8$ & $P<0.03$ \\
\hline Fat mass $(\mathrm{kg})$ & $21 \cdot 8$ & $6 \cdot 2$ & $21 \cdot 1^{* *}$ & $6 \cdot 3$ & $19 \cdot 7^{* * *}$ & $6 \cdot 7$ & $P<0.0001$ \\
\hline Fat mass $(\%)$ & $32 \cdot 6$ & 7.9 & $31.8^{*}$ & $8 \cdot 1$ & $30 \cdot 0^{* \star \star}$ & 9.4 & $P<0.0001$ \\
\hline $\mathrm{VO}_{2 \max }(\mathrm{ml} / \mathrm{min})$ & 1720 & 531 & 1792 & 534 & $1943^{\star * *}$ & 553 & $P<0.0001$ \\
\hline
\end{tabular}

$\mathrm{VO}_{2 \max }$, maximal oxygen uptake.

Mean values were significantly different from the corresponding values before training: ${ }^{\star} P<0.05,{ }^{* *} P<0.01,{ }^{* \star *} P<0.001$.

† Statistical level of significance of overall training effect on body composition as tested using a repeated-measures ANOVA design. 


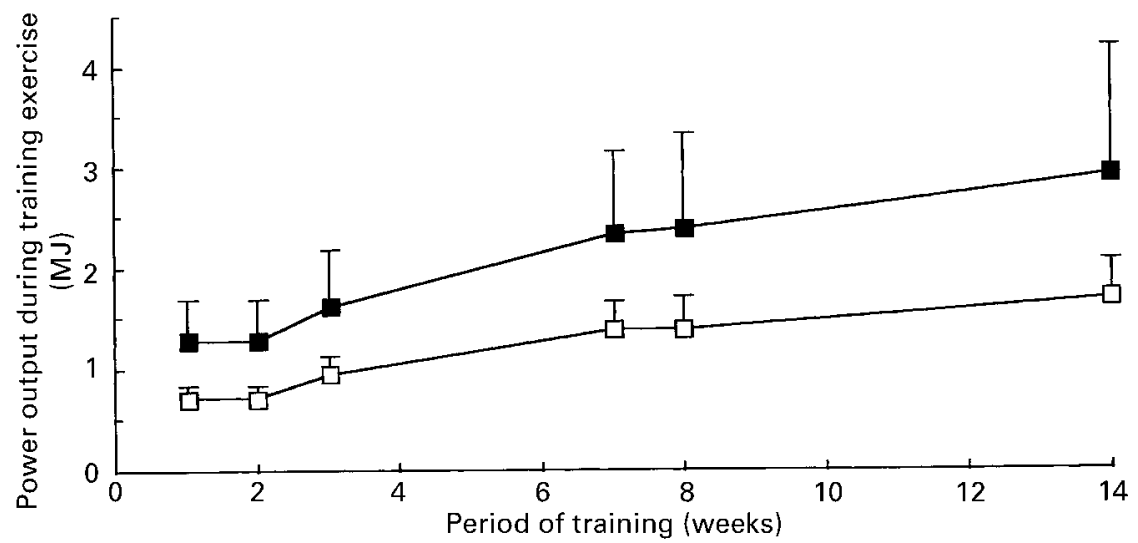

Fig. 2. Progressive increase in power output during training exercise in elderly men ( $\square$ ) and women ( $\square$ ) during a 14-week training period.

siesta, rest plus light seated activities, light standing activities, walk, leisure (e.g. gardening) plus sport activities, and training exercise (Table 2). Time spent walking decreased during the training period but no significant variations were found for the other activities.

DEE $_{\mathrm{FLC}}$ did not vary significantly throughout the training period (7 weeks $v$. before: +3.0 (SD 6.0) \%; 14 weeks $v$. before: +0.7 (SD 6.7) \%; Table 3). Moreover, DEE measured during the first day in the calorimeters while the subjects followed an activity programme adapted to their usual habits, did not vary significantly throughout the training period (7 weeks $v$. before: +3.0 (SD 8.9) \%; 14 weeks $v$. before: $+3 \cdot 8$ (SD 13.3) \%; Table 3).

Energy expended during sleep and siesta increased significantly by 6.9 (SD 8.2) \% after 7 weeks of training then returned to its initial level after 14 weeks of training.

Table 2. Time spent by elderly subjects in various categories of activities before, and after 7 and 14 weeks of endurance training

(Mean values and standard deviations for five men and eight women)

\begin{tabular}{|c|c|c|c|c|c|c|c|}
\hline \multirow[b]{2}{*}{ Time (min) } & \multicolumn{2}{|c|}{ Before } & \multicolumn{2}{|c|}{7 weeks } & \multicolumn{2}{|c|}{14 weeks } & \multirow[b]{2}{*}{ ANOVA* $^{*}$} \\
\hline & Mean & SD & Mean & SD & Mean & SD & \\
\hline Sleep and siesta & 527 & 69 & 536 & 60 & 535 & 54 & $P=0.76$ \\
\hline Rest and seated activities & 480 & 75 & 456 & 77 & 465 & 81 & $P=0.51$ \\
\hline Light to moderate standing activities & 283 & 86 & 295 & 73 & 296 & 75 & $P=0.73$ \\
\hline Walking & 115 & 61 & 83 & 48 & 91 & 59 & $P=0.04$ \\
\hline Leisure and sport activities & 35 & 20 & 48 & 47 & 33 & 36 & $P=0.39$ \\
\hline Training & 0 & & 21 & 4 & 20 & 4 & \\
\hline
\end{tabular}

* Statistical level of significance of overall training effect on time spent per category of activity as tested using a repeated-measures ANOVA design.

Table 3. Daily energy expenditure in elderly subjects calculated in free-living conditions using the factorial method $\left(D_{E} E_{F L C}\right)$ and measured during the first day in the calorimeters under free-living simulated conditions (DEE $E_{\text {USUAL }}$ ) before, and after 7 and 14 weeks of endurance training; $D E_{F L C}$ was broken up into three components: sleep, spontaneous activities and training exercises

(Mean values and standard deviations for five men and eight women)

\begin{tabular}{|c|c|c|c|c|c|c|c|}
\hline \multirow[b]{2}{*}{ Energy expenditure (MJ) } & \multicolumn{2}{|c|}{ Before } & \multicolumn{2}{|c|}{7 weeks } & \multicolumn{2}{|c|}{14 weeks } & \multirow[b]{2}{*}{ ANOVA† } \\
\hline & Mean & SD & Mean & SD & Mean & SD & \\
\hline $\begin{array}{l}\mathrm{DEE}_{\mathrm{FLC}} \\
\text { Sleeping EE } \\
\text { Free-living EE } \mathrm{E}_{\mathrm{ACT}} \\
\text { Training EE }\end{array}$ & $\begin{array}{r}10 \cdot 27 \\
2 \cdot 03 \\
8 \cdot 24 \\
0\end{array}$ & $\begin{array}{l}2.43 \\
0.62 \\
2.08\end{array}$ & $\begin{array}{c}10.55 \\
2 \cdot 16^{\star} \\
7 \cdot 80^{\star} \\
0.57\end{array}$ & $\begin{array}{l}2 \cdot 36 \\
0.63 \\
1.84 \\
0.14\end{array}$ & $\begin{array}{l}10 \cdot 33 \\
2 \cdot 06 \\
7 \cdot 67^{\star \star} \\
0.60\end{array}$ & $\begin{array}{l}2.47 \\
0.54 \\
2.07 \\
0.15\end{array}$ & $\begin{array}{l}P=0.34 \\
P=0.04 \\
P=0.02\end{array}$ \\
\hline DEE USUAL & 9.73 & $2 \cdot 46$ & 9.91 & $2 \cdot 14$ & 9.90 & 1.87 & $P=0.20$ \\
\hline
\end{tabular}

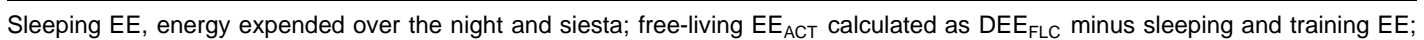
training EE, energy expended during training session.

Mean values were significantly different from the corresponding values before training: ${ }^{*} P<0.05,{ }^{* *} P<0.02$.

$\uparrow$ Statistical level of significance of overall training effect on energy expenditure as tested using a repeated-measures ANOVA design. 
Table 4. Daily energy expenditure ( $D E E_{\mathrm{CAL}}$ ) and its components measured in elderly subjects during the second day in the calorimeters under standardized conditions before, and after 7 and 14 weeks of endurance training

(Mean values and standard deviations for five men and eight women)

\begin{tabular}{|c|c|c|c|c|c|c|c|}
\hline & \multicolumn{2}{|c|}{ Before } & \multicolumn{2}{|c|}{7 weeks } & \multicolumn{2}{|c|}{14 weeks } & \multirow[b]{2}{*}{ ANOVA† } \\
\hline & Mean & SD & Mean & SD & Mean & SD & \\
\hline $\mathrm{DEE}_{\mathrm{CAL}}(\mathrm{MJ}$ over $24 \mathrm{~h}$ ) & 8.73 & 1.90 & 8.75 & 2.04 & 8.64 & 1.92 & $P=0.56$ \\
\hline SMR (MJ over $8 \mathrm{~h}$ ) & 1.85 & 0.45 & $1.93^{\star \star *}$ & 0.46 & 1.85 & 0.45 & $P<0.001$ \\
\hline BMR (MJ over $1 \mathrm{~h}$ ) & 0.26 & 0.07 & $0.28^{\star *}$ & 0.06 & 0.27 & 0.06 & $P<0.01$ \\
\hline Standard $\mathrm{EE}_{\mathrm{ACT}}(\mathrm{MJ}$ over $15 \mathrm{~h}$ ) & $6 \cdot 62$ & 1.40 & 6.54 & 1.54 & $6 \cdot 52$ & 1.42 & $P=0.56$ \\
\hline DIT (\% EI) $(n 9)$ & 3.7 & 2.5 & $7 \cdot 2^{*}$ & $2 \cdot 8$ & 4.2 & $2 \cdot 6$ & $P<0.01$ \\
\hline
\end{tabular}

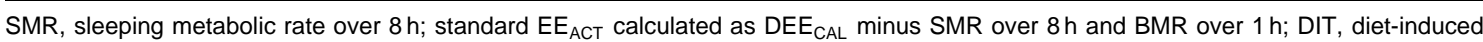
thermogenesis measured over $3.5 \mathrm{~h}$ in nine subjects and expressed as a percentage of energy intake $(\% \mathrm{El})$.

Mean values were significantly different from the corresponding values before training: ${ }^{*} P<0.05,{ }^{* *} P<0.02,{ }^{* *} P<0.001$.

$\dagger$ Statistical level of significance of overall training effect on energy expenditure as tested using a repeated-measures ANOVA design.

Energy expended during training sessions accounted for 5.5 (SD 1.3) \% and 6.0 (SD 1.6) \% of $\mathrm{DEE}_{\mathrm{FLC}}$ after 7 and 14 weeks of training respectively. Free-living $\mathrm{EE}_{\mathrm{ACT}}$ decreased progressively by $4.8($ SD 7.1$) \%(P<0.05)$ and $7.7(\mathrm{SD} 8.6) \%(P<0.01)$ after 7 and 14 weeks of training respectively.

\section{Energy expenditure under standardized conditions}

The activity programme was standardized during the second day in the calorimeters. The corresponding DEE did not vary significantly throughout the training period (Table 4$)$. However, SMR increased significantly by 4.6 (SD 3.2) \% after 7 weeks of training $(P<0.001)$ and returned to its initial level after 14 weeks of training (0.4 (SD 4.8) \%, $P=$ NS) (Table 4). Similarly, BMR was 7.6 (SD 7.0) \% $(P<0.01)$ and 4.1 (SD 6.1) \% $(P=\mathrm{NS})$ higher after 7 and 14 weeks of training respectively, than before training (Table 4). DIT variations could not be examined in the first four volunteers who had taken a snack before dinner. DIT, measured in nine subjects, increased significantly after 7 weeks of training $(P<0.05)$ and returned to its initial value after 14 weeks of training $(P=$ NS) (Table 4$)$. SMR, BMR and DIT alterations during the first 7 weeks and between weeks 7 and 14 of training were not correlated to changes in body composition and $\mathrm{VO}_{2 \max }$.

Energy expended while (1) sitting with very light activity, (2) eating, (3) standing with light-activity, (4) engaged in spontaneous activities, (5) walking at a given or at chosen speeds and (6) cycling at a given power output, did not vary significantly throughout the training period (Table 5).

Spontaneous chosen walking speed did not vary significantly throughout the training period. It was 3.9 (SD 1.0), 4.0 (SD 1.1) and $4.1($ SD 0.8$) \mathrm{km} / \mathrm{h}$ before, and after 7 and 14 weeks of training respectively. Because of the increase in $\mathrm{VO}_{2 \max }$, the relative intensity of walking at a given speed (i.e. $5.0(\mathrm{SD} 0.7) \mathrm{km} / \mathrm{h}$ ) decreased from 65.6 (SD 16.9) $\%$ $\mathrm{VO}_{2 \max }$ before training to 59.0 (SD 8.0) (7 weeks, $P=\mathrm{NS}$ ) and 57.1 (SD 13.2) $\% \mathrm{VO}_{2 \max }(14$ weeks, $P<0 \cdot 01)$. Similarly, cycling relative intensity at a given power output (i.e. 78 (SD 5) W) deceased from $73.2(\mathrm{SD} 5 \cdot 1) \% \mathrm{VO}_{2 \max }$ before training to $68.2(\mathrm{SD} 6 \cdot 6)(7$ weeks, $P<0.01)$ and 64.4 (SD 7.3) \% $\mathrm{VO}_{2 \max }(14$ weeks, $P<0 \cdot 001)$.

\section{Discussion}

The present study showed that $\mathrm{DEE}_{\mathrm{FLC}}$ of sedentary elderly subjects did not vary significantly throughout a 14-week

Table 5. Energy expended $(\mathrm{kJ} / \mathrm{h})$ by elderly subjects during standard and spontaneous activities as measured during the second day in the calorimeters (except for cycling) before, and after 7 and 14 weeks of endurance training (Mean values and standard deviations for five men and eight women)

\begin{tabular}{|c|c|c|c|c|c|c|c|}
\hline \multirow[b]{2}{*}{ Energy expended (kJ/h) } & \multicolumn{2}{|c|}{ Before } & \multicolumn{2}{|c|}{7 weeks } & \multicolumn{2}{|c|}{14 weeks } & \multirow[b]{2}{*}{ ANOVA $†$} \\
\hline & Mean & $\mathrm{SD}$ & Mean & SD & Mean & SD & \\
\hline Sitting with very light activity & 327 & 77 & 317 & 82 & 317 & 68 & $P=0.45$ \\
\hline Eating & 435 & 129 & 436 & 132 & 431 & 106 & $P=0.43$ \\
\hline Standing with light activity & 515 & 84 & 490 & 112 & $474^{* *}$ & 99 & $P=0.15$ \\
\hline Spontaneous activity $\ddagger$ & 385 & 73 & 369 & 81 & 372 & 74 & $P=0.32$ \\
\hline Walking at a given speed§ & 1187 & 286 & 1156 & 359 & 1201 & 328 & $P=0.17$ \\
\hline Walking at chosen speed & 925 & 294 & 915 & 315 & 917 & 315 & $P=0.91$ \\
\hline Cycling at a given power output $\|$ & 1580 & 456 & 1528 & 450 & 1575 & 463 & $P=0.22$ \\
\hline
\end{tabular}

Mean value was significantly different from the corresponding value before training, ${ }^{* *} P<0.02$.

$\dagger$ Statistical level of significance of overall training effect on energy expenditure as tested using a repeated-measures ANOVA design.

¥Energy expended during spare time.

§Walking at a given speed fixed before training (mean speed $5.0 \pm 0.7 \mathrm{~km} / \mathrm{h}$ ).

$\|$ Cycling at a given power output at the three stages of the study (mean power output $78 \pm 5 \mathrm{~W}$ ). Energy expended while cycling was determined from data obtained during the maximal aerobic power output test. 
training period despite (1) the energy cost of the training sessions, (2) transient increases in SMR, BMR and DIT and (3) changes in body composition. Therefore, elderly subjects progressively decreased their spontaneous activities as a result of endurance training.

Interval training was chosen as the method of endurance training because of its higher efficiency on physical capacity improvement compared with standard training at $50 \%$ of heart rate reserve in elderly people (Massé-Biron et al. 1993). During the first 2 weeks, the sedentary volunteers started training at a low level of intensity to get used to the effort on a cycle ergometer. Then, they were encouraged gradually to increase their effort. The highest level of intensity achieved above lactic threshold was chosen as the target. Moreover, duration of the training exercise was progressively increased since both intensity and duration of training exercise improve physical capacities (Cunningham et al. 1987). The training was therefore progressive throughout the whole protocol (Fig. 2). The distinction between the two stages of training (i.e. light-to-moderate intensity during the first 7 weeks and moderate-to-high intensity during the last 7 weeks) is artificial and related to the fact that metabolic measurements were performed at weeks 7 and 14 of the training protocol. In other respects, volunteers did not have exactly the same training schedule since intensity and duration of the training exercise were increased individually according to the feeling of fatigue. Values for mean relative intensity of training exercise were 61.1 (SD 6.4) and 63.0 (SD 6.2) \% $\mathrm{VO}_{2 \max }$ after 7 and 14 weeks of training respectively. Between-subject differences in the training programme could partly explain the large standard deviations for the changes in $\mathrm{VO}_{2 \max }$ and components of DEE.

Regarding the influence of endurance training on spontaneous activities and $\mathrm{DEE}_{\mathrm{FLC}}$ in elderly subjects, the present results are in agreement with conclusions from Goran \& Poehlman (1992). They contrast with results obtained in adults aged 28-41 years who did not alter significantly their spontaneous activities after 40 weeks of endurance training (Westerterp et al. 1994). In these younger adults, endurance training induced an increase in $\mathrm{DEE}_{\mathrm{FLC}}$.

The procedure used in the present study for the factorial method of calculating $\mathrm{DEE}_{\mathrm{FLC}}$ had been validated against the doubly-labelled water method in free-living elderly people (Morio et al. 1997b). Moreover, calculated $\mathrm{DEE}_{\mathrm{FLC}}$ values were in agreement with results from Goran \& Poehlman (1992) (10.3 MJ/d). The difference in the extent of the decline in free-living $\mathrm{EE}_{\mathrm{ACT}}$ between the present study $(-8 \%)$ and Goran \& Poehlman's (1992) study $(-62 \%)$ is probably due to the methods used for the calculations. In the present study, changes in energy expended during the time corresponding to free-living activities (i.e. DEE $_{\mathrm{FLC}}$ minus energy expended during sleep ( $8 \mathrm{~h})$ and during training sessions) were reported. The latter calculation was valid since energy expended per type of activity (measured in whole-body calorimeters) did not vary significantly with training. However, in the study of Goran \& Poehlman (1992), BMR was propagated over $24 \mathrm{~h}$ and DIT was estimated at $10 \%$ of $\mathrm{DEE}_{\mathrm{FLC}}$. In other words, the authors reported the energy expended during free-living activities above BMR and DIT. Therefore, the free-living
$\mathrm{EE}_{\mathrm{ACT}}$ they calculated was in absolute terms a smaller value than the one reported in the present study. Hence, any change in free-living $\mathrm{EE}_{\mathrm{ACT}}$ would be relatively larger. In the present study, the latter procedure resulted in a $26 \%$ decrease in free-living $\mathrm{EE}_{\mathrm{ACT}}$ after both 7 and 14 weeks of training $(P<0 \cdot 01)$.

This raises the question of training effects on energy cost of activities. In the present study, using calorimetric measurements, no significant variations were found in energy expended during various standard activities such as light seated activities, eating and light standing activities and spontaneous activities. In particular, energy expended while walking at a given speed for $30 \mathrm{~min}$ and while cycling at a given power output were examined: no significant variations were found throughout the training period. These results are in agreement with those obtained by Tzankoff et al. (1972) in fifteen middle-aged men, after 6 months of vigorous physical training. Lack of variations might be due to the $4 \cdot 7-8 \cdot 5 \%$ within-subject CV of energy expended during light-to-moderate intensity activities (Morio et al. 1997b). Therefore, no significant improvement in the efficiency of movement for walking and cycling could be demonstrated. Moreover, there was no apparent additive association between energy expended during physical activities and increased resting metabolic rate (SMR, BMR) as observed after 7 weeks of training.

In other respects, due to the improvement in the aerobic capacities of the volunteers, the relative intensity (expressed as $\% \mathrm{VO}_{2 \max }$ ) of walking and cycling at a given speed or power output decreased. This indicates a reduced strain during exercises (Tzankoff et al. 1972). This should have been beneficial to the subjects' well-being and probably made the performance of activities in free-living conditions easier. However, free-living $\mathrm{EE}_{\mathrm{ACT}}$ was reduced despite similar energy costs of activities. The decrease in time spent walking, and to a lesser extent in time spent seated while doing light activities, mainly explained the decrease in free-living $\mathrm{EE}_{\mathrm{ACT}}$. It is noticeable that time spent sleeping, and standing with light-to-moderate activities, tended to be higher during the training period than before the training began.

In elderly people, increasing (over a short period of time) the intensity of their activity above a threshold they are not used to reaching is sufficient to improve both body composition and physical capacities. Changes in body composition (i.e. FFM gain and fat mass loss) were in agreement with those reported by studies where subjects maintained a stable BW throughout an endurance training period (Meredith et al. 1989; Goran \& Poehlman, 1992; Poehlman et al. 1992). The decrease in FFM in the four subjects who lost $\mathrm{BW}$ demonstrates that it is important to maintain a stable BW in elderly people during endurance training. The $14 \%$ increase in $\mathrm{VO}_{2 \max }$ was within the range of published results in elderly subjects (10-22\%; Tzankoff et al. 1972; Meredith et al. 1989; Goran \& Poehlman, 1992; Poehlman et al. 1992). It is noteworthy that the increase in $\mathrm{VO}_{2 \max }$ was only observed during the second phase of the training period, when the subjects were exercising above lactic threshold.

Interestingly, from measurements obtained in the calorimeters, alterations in the main components of DEE differed 
between the first and second 7-week training periods. SMR and BMR significantly increased by $4.6 \%$ and $7.6 \%$ respectively, after 7 weeks of training. Thereafter, BMR slightly decreased and SMR returned to its initial value between weeks 7 and 14 of training. These transient alterations were observed despite a $3 \%$ (but not significant) increase in FFM. They could have resulted from the progressive nature of the training programme since intensity of exercises was below lactic threshold during the first 7 weeks and increased above lactic threshold during the last 7 weeks of training. In addition, a time-course effect of endurance training could also be suspected. The present results agree with the increase in BMR observed after 4-8 weeks of training in elderly people (Goran \& Poehlman, 1992; Poehlman et al. 1992, 1994). They are also in agreement with the lack of changes in BMR observed after 12 and 24 weeks of training in elderly subjects (Tzankoff et al. 1972; Meredith et al. 1989). They could also be related to the lower SMR observed in young adults after 44 weeks of running training despite a significant FFM gain (Westerterp et al. 1994). A longer training period would be necessary to study whether or not SMR and BMR would continue to decrease in elderly people.

It is well known that the calculation of DIT is subject to methodological problems (Tataranni et al. 1995). In the present study, DIT transiently increased from 4 to $7 \%$ energy intake after 7 weeks of training. These values are slightly lower than those obtained in elderly people (from 6 to $10 \%$ energy intake) (Golay et al. 1983; Pannemans et al. 1995; Visser et al. 1995), despite the high carbohydrate content of the standard meal. This could be due to the fact that measurements were taken at dinner while the subjects were non-fasted. In the literature, the impact of endurance training on DIT has not been studied in elderly subjects. In young adults, either no significant variations in DIT or a parallel increase in DIT with $\mathrm{VO}_{2 \max }$ have been reported after an endurance training programme (Pi-Sunyer \& Segal, 1992). The correlation between variations in DIT and $\mathrm{VO}_{2 \max }$ was not confirmed in the present study.

Three interrelated assumptions could partly explain the increases in SMR, BMR and DIT after 7 weeks of training without a significant FFM gain: (1) an increase in the sympathetic nervous system activity, (2) a higher sensitivity of peripheral tissues to catecholamines and/or (3) a higher sensitivity of peripheral tissues to insulin. It is well known that physical exercise stimulates catecholamine secretion. Half of the increase in BMR observed in elderly people after 8 weeks of moderate endurance training, was related to a $35 \%$ increased resting norepinephrine appearance flux (Poehlman et al. 1992). Moreover, Bahr et al. (1990) reported that physical exercise enhanced the lipolytic responsiveness of adipocytes to catecholamines by $20-$ $35 \%$. Catecholamines are known to stimulate substrate cycles which are energy consumers. It has been shown that physical exercise stimulates triacylglycerol-fatty acid cycling for several days in adipose tissue (Wolfe et al. 1990; Romijn et al. 1993). Moreover, catecholamines have been shown to stimulate in vitro the $\mathrm{Na}^{+}-\mathrm{K}^{+}$ATPase $(E C$ 3.6.1.3) activity which accounts for $5-40 \%$ of cellular energy consumption in muscle, liver and kidney (Ewart \& Klip, 1995). In addition, a training-induced increase in insulin sensitivity (Tonino, 1989; Yamanouchi et al. 1992) could improve the $\mathrm{Na}^{+}-\mathrm{K}^{+}$ATPase concentration at the muscle level (Schmidt et al. 1994). Between weeks 7 and 14 of training, the decreases in SMR, BMR and DIT could be explained by a down-regulation of $\beta$-adrenergic receptors or a reduced stress associated with exercise training (Kohrt et al. 1993). It seems unlikely that the decreases in SMR, BMR and DIT could be related to a loss of the insulin sensitivity gained during the first stage of the training period (Tonino, 1989; Yamanouchi et al. 1992).

In conclusion, $\mathrm{DEE}_{\mathrm{FLC}}$ remained constant throughout the training period, despite the additional energy cost of the training sessions. This was due to a compensatory decrease in free-living $\mathrm{EE}_{\mathrm{ACT}}$. The $8 \%$ decrease in freeliving $\mathrm{EE}_{\mathrm{ACT}}$ after 14 weeks of training was probably due to alterations in the type and intensity of daily activities. Furthermore, the progressive endurance training programme induced transient increases in SMR, BMR and DIT after 7 weeks of training which did not have significant consequences on energy expended during activities and on DEE.

\section{Acknowledgements}

The authors thank Dr Isabelle Rigaut, Elisabeth Verdier, Liliane Morin, Bruno Beaune, Pierre Gachon, Paulette Rousset and Guy Manlhiot for their cooperation and their skilled assistance, and Dr Jenny Jago and Caroline McCormack for revising the English. The authors are grateful to the volunteers for their participation in the study.

The present study was supported by Institut National de la Recherche Agronomique (INRA) and by CART Grant from Région Auvergne 1993.

\section{References}

Bahr R, Hansson P \& Sejersted OM (1990) Triglyceride/fatty acid cycling is increased after exercise. Metabolism 39, 993-999.

Chatard JC \& Denis D (1994) Aptitude physique du sujet âgé (Physical capacity in the elderly). Annales de Réadaptation Médicale et Physique 37, 423-429.

Coward WA (1990) Calculations of pool sizes and flux rates. In The Doubly-Labelled Water Method for Measuring Energy Expenditure. Technical Recommendations for Use in Humans, pp. 48-68 [AM Prentice, editor]. Vienna: IAEA.

Cunningham DA, Rechnitzer PA, Howard JH \& Donner AP (1987) Exercise training of men at retirement: a clinical trial. Journal of Gerontology 42, 17-23.

Durnin JVGA \& Womersley J (1974) Body fat assessed from total body density and its estimation from skinfold thickness: measurements on 481 men and women aged from 16 to 72 years. British Journal of Nutrition 32, 77-97.

Evans WJ (1996) Effects of aging and exercise on nutrition needs of the elderly. Nutrition Reviews 54, S35-S39.

Ewart HS \& Klip A (1995) Hormonal regulation of the $\mathrm{Na}^{+}-\mathrm{K}^{+}$-ATPase: mechanisms underlying rapid and sustained changes in pump activity. American Journal of Physiology 269, C295-C311.

Flynn MA, Nolph GB, Baker AS, Martin WM \& Krause G (1989) Total body potassium in aging humans: a longitudinal study. American Journal of Clinical Nutrition 50, 713-717.

Golay A, Schutz Y, Broquet C, Moeri R, Felber JP \& Jéquier E (1983) Decreased thermogenic response to an oral glucose load 
in older subjects. Journal of the American Geriatric Society 31, 144-148.

Goran MI \& Poehlman ET (1992) Endurance training does not enhance total energy expenditure in healthy elderly persons. American Journal of Physiology 263, E950-E957.

Hersey WC III, Graves JE, Pollock ML, Gingerich R, Shireman RB, Heath GW, Spierto F, McCole SD \& Hagberg JM (1994) Endurance exercise training improves body composition and plasma insulin responses in 70- to 79-year-old men and women. Metabolism 43, 847-854.

Horber FF, Kohler SA, Lippuner K \& Jaeger P (1996) Effect of regular physical training on age-associated alteration of body composition in men. European Journal of Clinical Investigation 26, 279-285.

Kohrt WM, Spina RJ, Ehsani AA, Cryer PE \& Holloszy JO (1993) Effects of age, adiposity, and fitness level on plasma catecholamine responses to standing and exercise. Journal of Applied Physiology 75, 1828-1835.

Massé-Biron J, Ahmaidi S, Adam B \& Préfaut C (1993) Intérêt d'un réentraînement aérobie individualisé au niveau du seuil ventilatoire chez des sujets âgés (Relevance of individualized aerobic training at ventilatory threshold in elderly people). Science et Sports 8, 251-259.

Meredith CN, Frontera WR, Fisher EC, Hughes VA, Herland JC, Edwards J \& Evans WJ (1989) Peripheral effects of endurance training in young and old subjects. Journal of Applied Physiology 66, 2844-2849.

Morio B, Beaufrère B, Montaurier C, Verdier E, Ritz P, Fellmann N, Boirie Y \& Vermorel M (1997a) Gender differences in energy expended during activities and in daily energy expenditure of elderly people. American Journal of Physiology 273, E321-E327.

Morio B, Ritz P, Verdier E, Montaurier C, Beaufrère B \& Vermorel M (1997b) Critical evaluation of the factorial and heart-rate recording methods for the determination of energy expenditure of free-living elderly people. British Journal of Nutrition 78, 709-722.

Pannemans DLE, Bouten CVC \& Westerterp KR (1995) $24 \mathrm{~h}-$ energy expenditure during standardized activity protocol in young and elderly men. European Journal of Clinical Nutrition 49, 49-56.

Pi-Sunyer FX \& Segal KR (1992) Relationship of diet and exercise. In Energy Metabolism: Tissue Determinants and Cellular Corollaries, pp. 187-210 [JM Kinney and HN Tucker, editors]. New York, NY: Raven Press Ltd.

Poehlman ET, Gardner AW, Arviero PJ, Goran MI \& CallesEscandon J (1994) Effects of endurance training on total fat oxidation in elderly persons. Journal of Applied Physiology 76, 2281-2287.

Poehlman ET, Gardner AW \& Goran MI (1992) Influence of endurance training on energy intake, norepinephrine kinetics, and metabolic rate in older individuals. Metabolism 41, 941-948.

Prentice AM (1992) Energy expenditure in the elderly. European Journal of Clinical Nutrition 46, Suppl. 3, 21-28.
Romijn JA, Klein S, Coyle EF, Sidossis S \& Wolfe RR (1993) Strenuous endurance training increases lipolysis and triglyceride-fatty acid cycling at rest. Journal of Applied Physiology $\mathbf{7 5}$, $108-113$.

Schmidt TA, Hasselbalch S, Farrell PA, Vestergaard H \& Kjeldsen K (1994) Human and rodent $\mathrm{Na}^{+}-\mathrm{K}^{+}$-ATPase in diabetes related to insulin, starvation, and training. Journal of Applied Physiology 76, 2140-2146.

Schoeller DA, Van Santen E, Peterson DW, Dietz W, Jaspan J \& Klein PD (1980) Total body water measurement in humans with ${ }^{18} \mathrm{O}$ and ${ }^{2} \mathrm{H}$ labeled water. American Journal of Clinical Nutrition 33, 2686-2693.

Siri WB (1956) The gross composition of the body. In Advances in Biological and Medical Physics, vol. 4, pp. 238-280 [CA Tobias and JH Lawrence, editors]. New York, NY: Academic Press.

Tataranni PA, Larson DE, Snitker S \& Ravussin E (1995) Thermic effect of food in humans: methods and results from use of a respiratory chamber. American Journal of Clinical Nutrition $\mathbf{6 1}$, 1013-1019.

Tonino RP (1989) Effect of physical training on the insulin resistance of aging. American Journal of Physiology 256, E352-E356.

Tzankoff SP, Robinson S, Pyke FS \& Brawn CA (1972) Physiological adjustments to work in older men as affected by physical training. Journal of Applied Physiology 33, 346350.

Vermorel M, Bitar A \& Vernet J (1995) Détermination des dépenses énergétiques des animaux et de l'homme par calorimétrie indirecte; 3, contrôle de la validité des mesures (Energy expenditure determination in animals and in humans using indirect calorimetry; 3 , check of measurement validity). Cahiers Techniques de l'INRA 35, 63-76.

Visser M, Deurenberg P, van Staveren WA \& Hautvast JGAJ (1995) Resting metabolic rate and diet-induced thermogenesis in young and elderly subjects: relationship with body composition, fat distribution, and physical activity level. American Journal of Clinical Nutrition 61, 772-778.

Weir JB de V (1949) New methods for calculating metabolic rate with special reference to protein metabolism. Journal of Physiology 109, 1-9.

Westerterp KR, Meijer GAL, Schffelen O \& Janssen EME (1994) Body mass, body composition and sleeping metabolic rate before, during and after endurance training. European Journal of Applied Physiology 69, 203-208.

Wolfe RR, Klein S, Carraro F \& Weber JM (1990) Role of triglyceride-fatty acid cycle in controlling fat metabolism in humans during and after exercise. American Journal of Physiology 258, E382-E389.

Yamanouchi K, Nakajima H, Shinozaki T, Chikada K, Kato K, Oshida Y, Osawa I, Sato J, Sato Y, Higuchi M \& Kobayashi S (1992) Effects of daily physical activity on insulin action in the elderly. Journal of Applied Physiology 73, 2241-2245. 


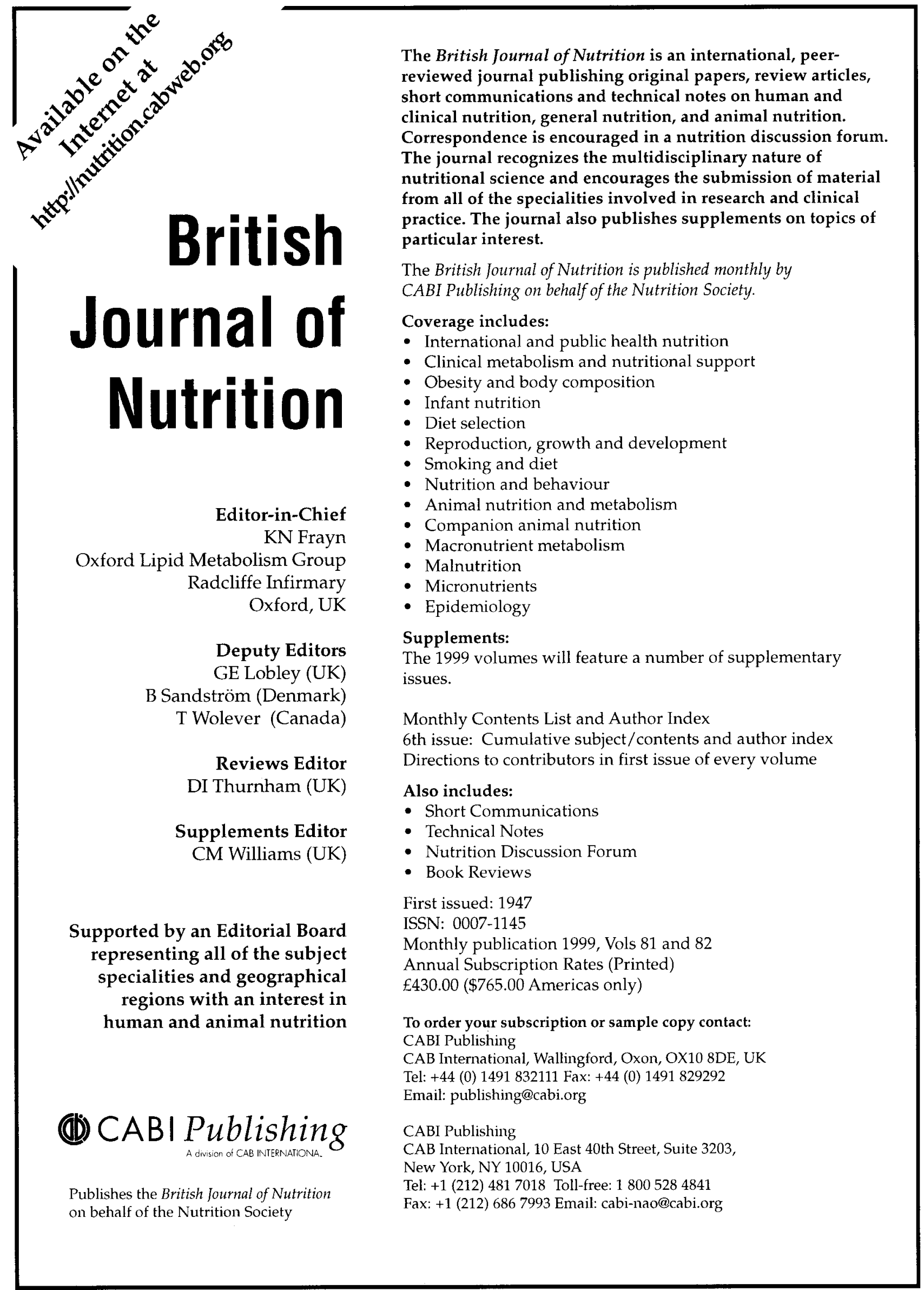

